\title{
Exposure of periodontal ligament progenitor cells to lipopolysaccharide from Escherichia coli changes osteoblast differentiation pattern
}

\author{
Mayra Laino ALBIERO, Bruna Rabelo AMORIM, Luciane MARTINS, Márcio Zaffalon CASATI, Enilson Antonio \\ SALLUM, Francisco Humberto NOCITI JR., Karina Gonzales SILVÉRIO
}

Department of Prosthodontics and Periodontics, Division of Periodontics, Piracicaba Dental School, UNICAMP - State University of Campinas, Piracicaba, SP, Brazil.

Corresponding address: Karina Gonzales Silvério - Departamento de Prótese e Periodontia, Área de Periodontia, Faculdade de Odontologia de Piracicaba Universidade de Campinas - UNICAMP - Av. Limeira, 901 - Areão - 13414-903 - Piracicaba - SP - Brazil - Phone/Fax: +55 1921065301 - e-mail: kgsilverio@ fop.unicamp.br

Submitted: September 2, 2014 - Modification: November 21, 2014 - Accepted: December 1, 2014

\section{ABSTRACT}

\begin{abstract}
Deriodontal ligament mesenchymal stem cells (PDLMSCs) are an important alternative source of adult stem cells and may be applied for periodontal tissue regeneration, neuroregenerative medicine, and heart valve tissue engineering. However, little is known about the impact of bacterial toxins on the biological properties of PDLSMSCs, including self-renewal, differentiation, and synthesis of extracellular matrix. Objective: This study investigated whether proliferation, expression of pro-inflammatory cytokines, and osteogenic differentiation of CD105-enriched PDL progenitor cell populations (PDL-CD105+ cells) would be affected by exposure to bacterial lipopolysaccharide from Escherichia coli (ECLPS). Material and Methods: Toll-like receptor 4 (TLR4) expression was assessed in PDL-CD $105^{+}$cells by the immunostaining technique and confirmed using Western blotting assay. Afterwards, these cells were exposed to EcLPS, and the following assays were carried out: (i) cell viability using MTS; (ii) expression of the interleukin-1 beta (IL-1 $\beta$ ), interleukin-6 (IL-6), interleukin-8 (IL-8), and tumor necrosis factor alpha (TNF- $\alpha$ ) genes; (iii) osteoblast differentiation assessed by mineralization in vitro, and by mRNA levels of runrelated transcription factor-2 (RUNX2), alkaline phosphatase (ALP) and osteocalcin (OCN) determined by quantitative PCR. Results: PDL-CD105+ cells were identified as positive for TLR4. EcLPS did not affect cell viability, but induced a significant increase of transcripts for IL-6 and IL-8. Under osteogenic condition, PDL-CD105+ cells exposed to EcLPS presented an increase of mineralized matrix deposition and higher RUNX2 and ALP MRNA levels when compared to the control group. Conclusions: These results provide evidence that CD105enriched PDL progenitor cells are able to adapt to continuous Escherichia coli endotoxin challenge, leading to an upregulation of osteogenic activities.
\end{abstract}

Keywords: Cell differentiation. Bacterial antigens. Periodontal ligament. Stem cells. Osteogenesis.

\section{INTRODUCTION}

The great differentiation capacity of mesenchymal stem cells (MSCs), the possibility of grafting, and its expansion in culture led to an increased interest in the clinical use of these cells through directed administration on specific sites in many pathological situations. In this sense, regenerative therapy based on stem cells has gained attention since the isolation of mesenchymal stem cells from various tissues.

The search for similar cells to mesenchymal stem cells in specific tissues has led to the discovery of a variety of stem cells in almost all organs and tissues of the body in recent decades ${ }^{20}$. Dental tissue is a potent reservoir of postnatal stem/progenitor cells isolated from dental pulp ${ }^{4}$, periodontal ligament from permanent ${ }^{21}$ and deciduous teeth ${ }^{22}$, apical papilla ${ }^{24}$, or dental follicles ${ }^{17}$. These postnatal 
populations cells have been characterized by the expression of specific surface markers to mesenchymal stem cells (CD105, CD166, CD73 e STRO1) $)^{21,22}$, and have stem cells-like properties, including the capacity for self-renewal and multilineage differentiation potential ${ }^{6}$. Periodontal ligament mesenchymal stem cells (PDLSCs) are an important alternative source of adult stem cells and may be applied in periodontal tissue regeneration ${ }^{21,25}$, neuroregenerative medicine ${ }^{3}$, and heart valve tissue engineering ${ }^{14}$. Although PDLSCs can be routinely isolated and cultivated from periodontal ligament, many issues have to be approached before these cells can be used for therapies, such as their growth and differentiation in the presence of bacterial toxins, which may be present in many clinical situations.

Lipopolysaccharide (LPS) is an endotoxin present in Gram-negative bacteria such as Escherichia coli. This endotoxin, when in contact with cells of the host immune system, as well as gingival fibroblasts, induces an immune-inflammatory response characterized by the release of pro-inflammatory cytokines, which are mediated by Toll-like receptors (TLR2 e TLR4) ${ }^{9}$. The feasibility of using PDLSCs in regenerative procedures by virtue of their capacity to differentiate into multiple cell lines depends on whether the growth and osteogenic differentiation of PDLSCs are affected by bacterial stimuli. Some studies suggest that periodontal ligament cells may alter their phenotype in response to inflammation promoted by bacterial lipopolysaccharide ${ }^{23,27}$. However, little is known about the interactions between bacteria and MSCs. Recently, it was observed $^{16}$ that an in vitro change in osteogenic differentiation pattern occurs when mesenchymal stem cells isolated from the bone marrow of healthy individuals were exposed to the Escherichia coli LPS.

Thus, this study investigated the effects of lipopolysaccharides from Escherichia coli (EcLPS) on cell viability, expression of pro-inflammatory cytokines, and osteogenic differentiation potential of CD105-enriched PDL progenitor cell populations.

\section{MATERIAL AND METHODS}

\section{Cell culture}

This study was approved by the Institutional Review Board (\#022/2011). Five populations of mesenchymal progenitor cells $\left(\mathrm{STRO} 1^{+} \mathrm{CD} 105^{+}\right.$ CD166+ CD34-CD45- cells) from periodontal dental ligament (PDL) of permanent teeth were obtained and characterized in a previous study ${ }^{22}$. Briefly, teeth extractions of completely erupted third molars of five subjects (aged 19 to 22 years) were performed at the Dental Clinic of the School of Dentistry, State University of Campinas, Piracicaba, São Paulo, Brazil. Teeth were placed in biopsy media composed of Dulbecco's modified Eagle's medium (DMEM) supplemented with $10 \%$ fetal bovine serum, 250 $\mathrm{mg} / \mathrm{ml}$ gentamicin sulfate, $5 \mathrm{~m} / \mathrm{ml}$ amphotericin $\mathrm{B}$, and $1 \%$ penicillin/streptomycin (Gibco BRL, Life Technologies, Carlsbad, CA, USA), and transferred to the laboratory facilities. The PDL tissues from permanent teeth were gently scraped from the mid-portion of the root surface and enzymatically digested in a solution of $3 \mathrm{mg} / \mathrm{ml}$ collagenase type II (Gibco BRL) and $4 \mathrm{mg} / \mathrm{ml}$ dispase (Gibco BRL) for 1 hour at $37^{\circ} \mathrm{C}$. Heterogeneous single-cell suspensions were obtained by passing the cells through a 70-mm cell strainer (Falcon, BD Labware, Franklin Lakes, NJ, USA). Samples were expanded in $25 \mathrm{~cm}^{2}$ culture flasks (Falcon) at $37^{\circ} \mathrm{C}, 5 \% \mathrm{CO}^{2}$ in DMEM supplemented with $10 \%$ fetal bovine serum, $1 \% \mathrm{~L}$ glutamine and $1 \%$ penicillin/streptomycin (Gibco BRL) (standard media). CD105 ${ }^{+}$enriched cell subsets from PDL (PDL-CD105+ cells) were isolated by magnetic cell sorting, and characterized by flow cytometry, and immunostaining. Flow cytometric analysis demonstrated a higher proportion of CD $105^{+}$cells co-expressing CD166 surface antigen, whereas immunostaining demonstrated expression of STRO-1. These cell populations showed multipotential capabilities to differentiate in vitro into an osteoblast phenotype and adipocytelike cells ${ }^{22}$. All five PDL-CD105+ cell populations were cultured in Dulbecco's modified Eagle's minimal essential medium (DMEM) supplemented with $10 \%$ fetal bovine serum, $1 \% \mathrm{~L}$ glutamine and $2 \%$ penicillin/streptomycin (standard media) (Gibco $B R L)$, frozen with Recovery ${ }^{\mathrm{TM}}$ Cell Culture Freezing Medium (Gibco BRL) and kept in liquid nitrogen for subsequent experiments.

\section{Preparation of LPS solution from Escherichia coli}

Bacterial LPS were suspended in $1 \mathrm{~mL}$ of sterile and endotoxin-free water as a stock solution (concentration $1 \mathrm{mg} / \mathrm{mL}$ ) of Escherichia coli (SigmaAldrich, St Louis, MO, USA), and stored at $-20^{\circ} \mathrm{C}$. At the time of each experiment, the concentrations of $100 \mathrm{ng} / \mathrm{mL}, 1 \mu \mathrm{g} / \mathrm{mL}$ e $10 \mu \mathrm{g} / \mathrm{mL}^{10}$ were obtained by diluting each LPS in DMEM from the stock solution.

\section{Immunostaining for TLR4}

To evaluate the expression pattern of Toll-like receptor 4 (TLR4), PDL-CD $105^{+}$cell populations were seeded at $4 \times 10^{4}$ cells/well on glass coverslips (13 mm, Knittel ${ }^{\circledR} \mathrm{GmbH}$, Braunschweig, Germany), placed in 24-well plates (Falcon), and cultured for 24 hours in standard media. Afterwards, cells were fixed in $4 \%$ paraformaldehyde for 10 minutes, blocked with $3 \%$ bovine serum albumin (BSA, Sigma-Aldrich) for 30 minutes, and incubated with a mouse antihuman TLR4 antibody (1:50; Abcam, Cambridge, MA, UK) for $1 \mathrm{~h}$. Subsequently, cells 
were incubated with a secondary antibody Goat antimouse IgG Alexa fluor 488 (1:1000) (Invitrogen, Carlsbad, CA, USA) for 1 hour. In order to identify nuclei, the samples were counterstained with TO$\mathrm{PRO}^{\circledR}-3$ iodide 642/661 (1:2000) (Invitrogen) for 15 minutes. As a negative control, cells were incubated only with the secondary antibody. Samples were then analyzed by confocal laser scanning microscopy (Leica TCS SP5AOBS, Mannheim, Germany).

\section{Western Blot analysis for TLR4}

Total cellular protein was extracted from cultured PDL-CD105+ cell populations using the RIPA buffer (Thermo Scientific, Rockford, IL, USA) supplemented with protease inhibitor cocktail (Sigma, P2714), following the manufacturer's specifications. Protein concentration was measured by the Bradford method (Bio-Rad Laboratories, Benicia, CA, USA) with bovine serum albumin (BSA) as a standard, and was measured spectrophotometrically at $595 \mathrm{~nm}$. Equal amounts of protein per sample were separated by sodium dodecyl sulphate polyacrylamide gel electrophoresis (SDS-PAGE) 10\% and transferred to a nitrocellulose membrane (Amersham ${ }^{\mathrm{TM}}$ Hybond $\mathrm{ECL}$, Amersham BioSciences ${ }^{\mathrm{TM}}$, GE Healthcare, Little Chalfont, Buckinghamshire, UK). The membranes were blocked with $3 \%$ BSA in TBS for $1 \mathrm{~h}$ at room temperature, incubated overnight with a $1: 1000$ dilution of primary antibody mouse anti-human TLR4 (Abcam), and then incubated with peroxidaseconjugated secondary antibodies (Anti-mouse 1:2500) (Santa Cruz Biotechnology, Dallas, TX, USA) for $2 \mathrm{~h}$. The membrane was developed using an ECL reagent (SuperSignal West Femto Substrate, Thermo Scientific) and the signals were detected using radiographic films (Kodak, Rochester, NY, USA).

\section{Cell viability assay}

The MTS assay was used to determine cell viability of PDL-CD105+ cells. Single-cell suspensions $\left(1.5 \times 10^{4}\right.$ cells/well) were seeded on 96 -well plates with standard media for $24 \mathrm{~h}$ for cell attachment and spreading. Subsequently, media was changed to standard medium containing $0,100 \mathrm{ng} / \mathrm{mL}, 1 \mu \mathrm{g} /$ $\mathrm{mL}$ or $10 \mu \mathrm{g} / \mathrm{mL}$ concentrations of EcLPS, and cells were cultured for 10 days. At time points of 1, 3, 7, and 10 days, MTS reagent (Promega Co., Madison, WI, USA) was added, and cells were incubated for $2 \mathrm{~h}$ at $37^{\circ} \mathrm{C}$ in a humidified $\mathrm{CO}_{2}$ incubator. The absorbance of the formed formazan dye was measured photometrically at $490 \mathrm{~nm}$.

\section{Cytokines gene expression}

Cells were seeded on a $60-\mathrm{mm}$ dish $\left(2 \times 10^{5}\right.$ cells/ dish) with standard media for $24 \mathrm{~h}$. Subsequently, media was changed to standard media supplemented with $0,100 \mathrm{ng} / \mathrm{mL}, 1 \mu \mathrm{g} / \mathrm{mL}$ or $10 \mu \mathrm{g} / \mathrm{mL}$ of EcLPS. After 24 hours, total RNA was obtained using TRIzol ${ }^{\circledR}$ reagent (Invitrogen) to determine the expression of transcripts corresponding to interleukin- 1 beta (IL-1 $\beta$ ), interleukin 6 (IL-6), interleukin 8 (IL-8), and tumor necrosis factor alpha (TNF- $\alpha$ ).

\section{Osteogenic induction}

PDL-CD105+ cells were seeded $2 \times 10^{5}$ in 60$\mathrm{mm}$ tissue culture dishes in standard media for gene expression analysis and in 24-well plates to assess the mineral nodule formation in vitro. After 24 hours, standard medium was changed to an osteogenic-inducing medium (DMEM 10\% FBS, 50 $\mu \mathrm{g} / \mathrm{ml}$ ascorbic acid, $10 \mathrm{mM} \beta$-glycerol-phosphate, $10^{-8} M$ dexamethasone). To evaluate the effect of LPS on osteogenic differentiation, the differentiation medium was also supplemented with $1 \mu \mathrm{g} / \mathrm{mL} E$. coli LPS. Total RNA was obtained using a reagent (TRIzol ${ }^{\circledR}$, Invitrogen) at days 3, 7, and 14 for the determination of the expression of transcripts corresponding to ALP, OCN, and RUNX2. In parallel, in vitro mineral nodule formation was assessed at day 21 using the alizarin Red assay (Sigma-Aldrich). For that, after 21 days of differentiation, cells were fixed with $70 \%$ ethanol and stained with alizarin Red (Sigma-Aldrich) for calcium detection. For

\begin{tabular}{|l|c|c|c|}
\hline \multicolumn{1}{|c|}{ Gene } & Foward Primer & Reverse Primer & Amplicon \\
\hline ALP & 5'-cgggcaccatgaaggaaa-3' & 5'-ggccagaccaaagatagagtt-3' & 184 \\
\hline OCN & 5'-agctcaatccggactgt-3' & 5'-ggaagaggaaagaagggtgc-3' & 150 \\
\hline RUNX2 & 5'-ccgtccatccactctaccac-3' & 5'-atgaaatgcttgggaactgc-3' & 139 \\
\hline IL-1 $\beta$ & 5'-cttcttcgacacatgggataac-3' & 5'-tttgggatctacactctccagc-3' & 283 \\
\hline IL-6 & 5'-ctagagtacctccagaacagatttga-3' & 5'-tcagcaggctggcattt-3' & 154 \\
\hline IL-8 & 5'-gccaagagaatatccgaactttaat-3' & 5'-ctggctagcagactaggg-3' & 172 \\
\hline TNF- $\alpha$ & 5'-tccacccatgtactcctcac-3' & 5'-cctcccagatagatgggctcata-3' & 155 \\
\hline GAPDH & 5'-acatcatccctgcctctac-3' & 5'-ccaccttcttgatgtcatcatatttg-3' & 171 \\
\hline
\end{tabular}

ALP, alkaline phosphatase; OCN, osteocalcin; RUNX-2, runt-related transcription factor 2; IL-1 1 , interleukin-1 beta; IL-6, interleukin 6; IL-8, interleukin 8; TNF- $\alpha$, tumor necrosis factor alpha; GAPDH, glyceraldehyde-3-phosphate dehydrogenase

Figure 1- Primers sequence used for amplification in real-time PCR 
quantitative measurement, alizarin was solved in a $10 \%$ cetylpyridinium chloride monohydrate solution (PBS) for 15 min and samples were measured in a plate reader at $562 \mathrm{~nm}$.

\section{Gene expression analysis}

Total RNA was DNase treated (Turbo DNAfree, Ambion, Foster City, CA, USA), and singlestranded complementary DNA (cDNA) was synthetized from $1 \mu \mathrm{g}$ of total RNA using a kit (First Strand CDNA synthesis kit, Roche Diagnostics, Indianapolis, IN, USA) following the manufacturer's recommendations. Primers sequences for ALP, OCN, RUNX2, IL-1 $\beta$, IL-6, IL-8, TNF- $\alpha$ and glyceraldehyde-3-phosphate dehydrogenase (GAPDH) are shown in Figure 1. qRT-PCR was performed with the LightCycler 2.0 and software (Roche Diagnostics GmbH, Mannheim, Germany), using the FastStart DNA Master plus SYBR Green Kit (Roche Diagnostics). Water (no template) was used as a negative control for all experiments. Relative quantification of reaction products was accomplished using GAPDH as the reference gene.

\section{Statistical analysis}

All experiments were performed in triplicate and repeated on at least three separate occasions. Mean and standard deviation were obtained to establish statistical comparisons. Data comparison was performed using one-way analysis of variance test $(\alpha=0.05)$, and pairwise multiple-comparison test (Tukey test) was used to identify the difference among the groups. Additionally, non-parametric Kruskal-Wallis test $(a=0.05)$ followed by the Student-Newman-Keuls was performed to assess the effect of LPS on cytokines gene expression (BioEstat 5.0, Belém, PA, Brazil).

\section{RESULTS}

\section{PDL-CD105+ cells express LPS receptor}

Immunofluorescence analysis revealed that PDL-CD $105^{+}$cells exhibited positive staining for TLR4, which is a specific molecule involved in $E$. coli LPS signaling pathways (Figures $2 \mathrm{~A}$ and $2 \mathrm{~B}$ ). This positivity for TLR4 was confirmed by the Western blotting analysis, showing that all five cell populations assessed expressed this receptor (Figure 2C).

\section{E coli LPS induces PDL-CD105+ response}

To verify whether PDL-CD105+ cells responded to E. coli LPS, a metabolic activity as an indicator for cell viability was first measured using MTS assay. All PDL-CD $105^{+}$populations from five donors were able to retain the capacity to form adherent colonies and fibroblast spindle-shape after exposure to $E$. coli LPS (data not presented). As shown in Figure 3A, LPS did not affect the proliferation of PDL-CD105+ cells during the 10-day period, even after incubation with a relatively high concentration of endotoxin (1 $\mu \mathrm{g}$ and $10 \mu \mathrm{g} / \mathrm{mL}$ ). In addition, MTS values showed a time-dependent increase of cell proliferation in all groups, with a higher number of cells after 3 and 7 days in the culture (Figure 3A).

Next, a qRT-PCR was performed to assess gene expression changes on pro-inflammatory cytokines IL- $1 \beta$, TNF- $\alpha$, IL- 6 and IL- 8 in PDL-CD $105^{+}$cells. After $24 \mathrm{~h}$ of toxin challenge, EcLPS at concentrations of $100 \mathrm{ng}$ and $1 \mu \mathrm{g} / \mathrm{mL}$ induced a significant increase of the transcripts for IL- 6 and IL- 8 compared to the control group (Figure 3B). Despite the fact that PDL-CD $105^{+}$cells only expressed IL-1 $\beta$ and TNF-a mRNA after LPS challenge, there were no
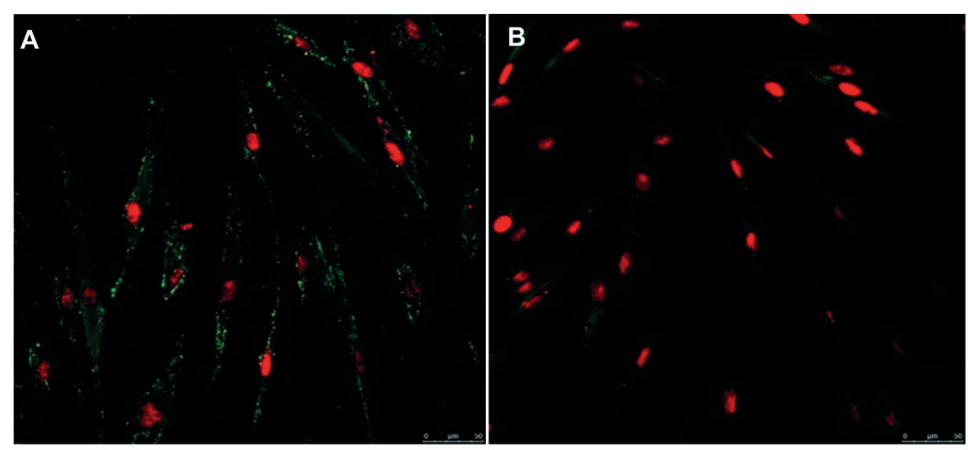

C

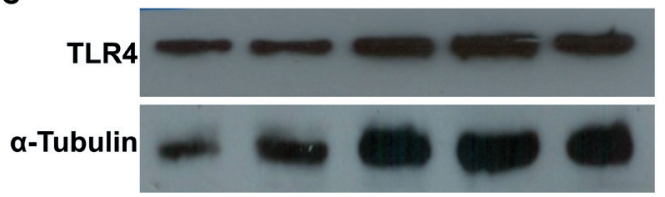

Figure 2- Highly purified CD105+ subsets of periodontal ligament (PDL) cells express Toll-like receptor 4 (TLR4). (A) Positive immunofluorescence for the TLR4 with nuclear localization confirmed by TO-PRO ${ }^{\circledR} 3$ staining. (B) Control are represented by PDL-CD105+ cells incubated only with secondary antibody. (C) Western blotting analysis confirmed TLR4 in the five PDL-CD105+ cells 
significant differences between cell exposed versus non-exposed, probably due to the greater variability of IL-1 $\beta$ and TNF- $\alpha$ expression among the five populations (Figure 3B).

\section{LPS challenge enhances osteogenic differentiation of PDL-CD105+ cells}

Having demonstrated that EcLPS (100 ng and $1 \mu \mathrm{g} / \mathrm{mL}$ ) induced a pro-inflammatory cytokines response in PDL-CD105+ cells, next it was investigated whether EcLPS could change the osteogenic properties of these cells. For this evaluation, cells were only exposed to EcLPS at concentration of $1 \mu \mathrm{g} / \mathrm{mL}$, and mineral nodule deposits (Alizarin Red staining) and gene expression of osteogenic markers (RUNX2, ALP, and OCN) were assessed.

After three weeks of osteogenic induction, mineral nodule formation could be observed in osteogenic differentiated cells of the positive control, as demonstrated by the quantification of Alizarin Red crystals (Figure 4A). This mineral deposition was increased when cells were exposed to osteogenic medium and E. coli LPS (Figure 4A). No mineralized nodules were observed in cells cultured in the DMEM used as a control (Figure
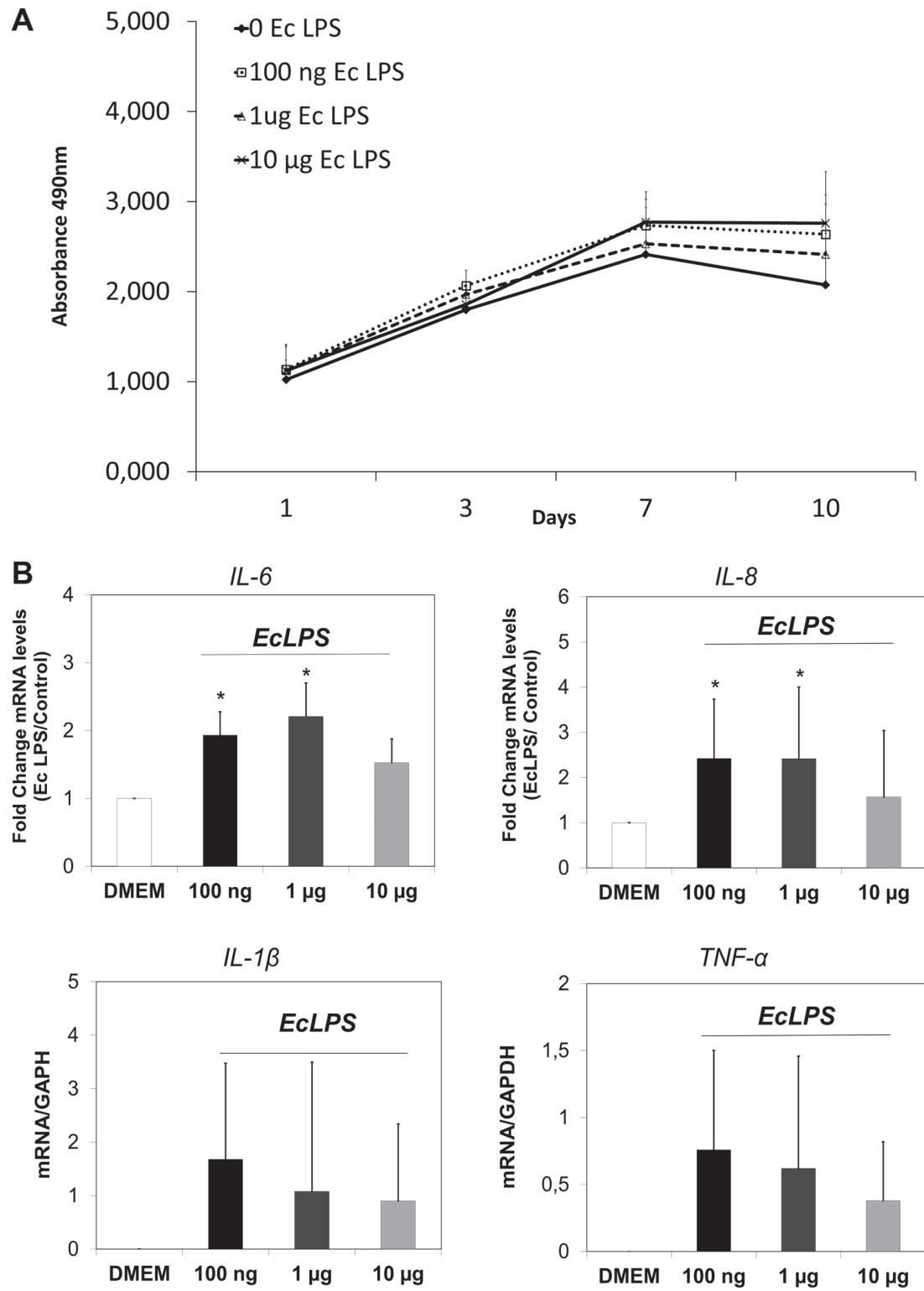

Figure 3- Effect of E. coli lipopolysaccharide (LPS) on the viability and pro-inflammatory cytokines expression. (A) PDL$\mathrm{CD}_{105^{+}}$cells were cultured in the presence of EcLPS at concentrations of 0, $100 \mathrm{ng}, 1 \mu \mathrm{g}$ and $10 \mu \mathrm{g} / \mathrm{ml}$. Metabolic activity as an indicator for cell viability was measured with MTS assay at the following time points: 1, 3, 7 and 10 days. (B) Realtime PCR showed an increase of mRNA levels of IL-6, IL-8, IL-1 $\beta$ and TNF- $\alpha$, respectively, in PDL-CD105+ cells after 24 hours of EcLPS exposure. Representative data of three independent experiments are shown. Statistical significance intergroup is indicated by * $(p<0.05)$ 
A 800

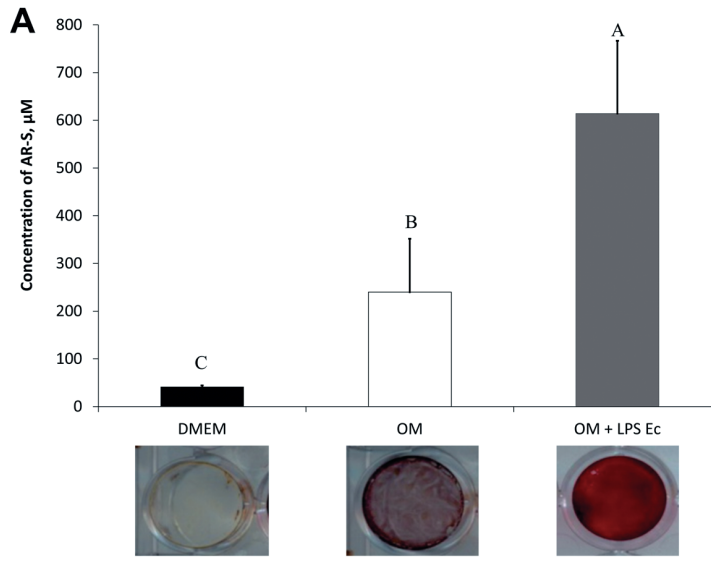

ALP

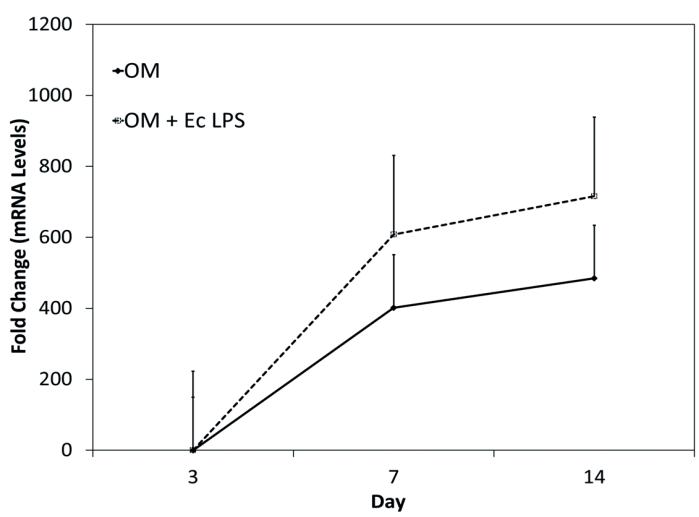

B $\quad$ RUNX2

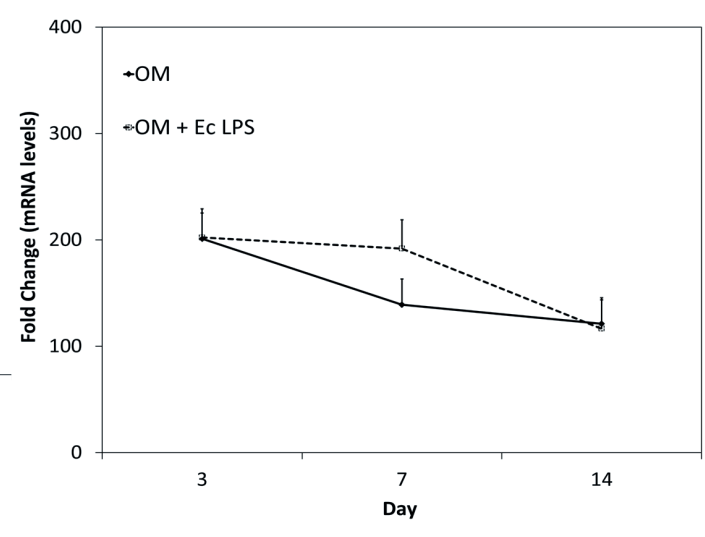

OCN

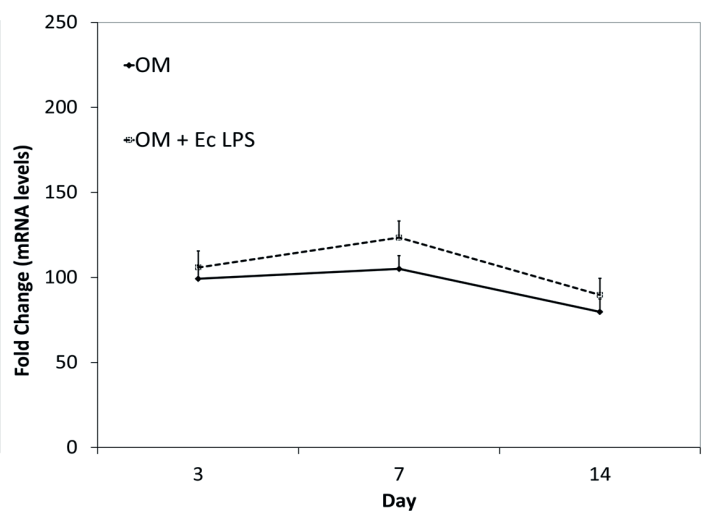

Figure 4- Osteoblast differentiation of PDL-CD105+ cells under EcLPS exposure. (A) Quantification of Alizarin Red staining showed that EcLPS at concentration of $1 \mu \mathrm{g} / \mathrm{ml}$ increased mineral nodule formation at $21 \mathrm{~d}$. (B) PDL-CD $105^{+}$cells were cultured in osteogenic medium (OM) alone or in OM+EcLPS $(1 \mu \mathrm{g} / \mathrm{ml})$. Data are presented as fold increase relative to non-induced controls for quantitative real-time PCR analysis showing that EcLPS did not alter the expression pattern of mRNAs for RUNX2, ALP, and OCN. All genes tested were normalized to the corresponding housekeeping gene, GAPDH. Representative data of three independent experiments are presented. Bars in (A) represent mean \pm standard deviation (SD) where intergroup statistical differences analysis are indicated by different capital letters $(p<0.05)$

4A). QRT-PCR analysis further demonstrated an increased expression of a key osteoblast transcription factor, RUNX2, and two osteoblastspecific early/late differentiation transcripts (ALP and $\mathrm{OCN}$, respectively) in osteogenically-induced cells compared to non-induced (Figure 4B). When cells were cultured in an osteogenic medium supplemented with E. coli LPS, higher levels of transcripts for RUNX2, ALP, and OCN were found on day 7 after osteogenic induction (Figure 4B), although there is no significant differences between cells induced and non-induced with bacterial toxin. However, taken together, these data suggest that LPS challenge enhances osteogenic differentiation of PDL-CD $105^{+}$cells.

\section{DISCUSSION}

This study investigated the effects of LPS from enterobacteria Escherichia coli on CD105-enriched PDL progenitor cell populations (PDL-CD105+ cells). The surface marker CD105 was chosen for sorting progenitor cells from PDL heterogeneous population, since it is the most frequently reported positive surface marker in $\mathrm{MSCs}^{22}$. In addition, the expression of CD105 is one of the minimal criteria to define human MSCs according to the Mesenchymal and Tissue Stem Cell Committee of the International Society for Cellular Therapy ${ }^{2}$. As part of cell characterization, the present study showed that TLR4 was expressed by CD105-enriched PDL progenitor cell populations. This finding is in accordance with previous studies which have also reported that TLR4 are expressed by mesenchymal stem cells such as bone marrow mesenchymal stem cells $\mathbf{s}^{7,13}$ and periodontal ligament stem cells ${ }^{13}$. The family of the Toll-like receptors is involved in recognition of bacterial cell wall components ${ }^{15}$, and it has been described that E. coli LPS trigger an inflammatory environment by binding to TLR $4^{1,7,13}$.

To evaluate the influence of $E$. coli-derived LPS on cell proliferation, CD105-enriched PDL progenitor cell populations were initially cultured in the presence of different concentrations of this 
bacterial toxin. The findings showed that cells remained viable and proliferative regardless of the LPS concentration. These data corroborate the findings of other studies, which assessed the effect of Escherichia coli endotoxins in pre-osteoblastic cells ${ }^{11}$, bone marrow mesenchymal stem cells ${ }^{14}$, adipose-derived stromal cells ${ }^{8}$, and dental follicle stem cells ${ }^{18}$.

Since LPS from $E$. coli did not change cell growth, it was determined whether this endotoxin had any effect on cellular inflammatory response. It was found that ECLPS induced a significant expression of IL- 6 and IL- 8 in PDL-CD105+ cells. In addition, this bacterial toxin was able to induce the expression of two pro-inflammatory cytokines, IL-1 $\beta$ and TNF-a. However, there were no significant differences between PDL-CD105+ cells exposed to ECLPS versus non-exposed, probably due to the greater variability of IL- $1 \beta$ and TNF-a expression among the five cell populations. Similar to our data, previous studies had already observed an inflammatory response of oral cells exposed to LPS from $E$. coli. The expression of IL- 6 and IL- 8 were induced in periodontal ligament cells ${ }^{26}$, while in dental follicle stem cells (DFCs) the gene for IL-1 $\beta$ could also be observed after exposure to EcLPS ${ }^{18}$.

Some evidences of the literature supports the notion that inflammatory environment mediated by lipopolysaccharides can inhibit osteoblast differentiation of human periodontal ligament stem cells ${ }^{12,13}$, mouse bone marrow mesenchymal stem cells ${ }^{7}$, and osteoblastic precursor cell line - MC3T3-E15. It has been suggested that LPS decreases the osteogenic potential of mesenchymal stem cells through TLR4 regulated nuclear factor (NF)-kB pathway ${ }^{7,13}$. Further, in osteoblastic precursor cells (MC3T3-E1), LPS seems to induce cell apoptosis and inhibit osteoblast differentiation via c-Jun N-terminal kinases (JNK) pathway ${ }^{5}$.

Our findings demonstrated that the inflammatory response induced by $E$. coli LPS did not affect the osteoblast differentiation of CD105-enriched PDL progenitor cell populations. Unlike the studies cited above $^{5,7,12,13}$, EcLPS challenge increased mineralized nodules deposition through the osteogenic induction in PDL-CD105+ cells. Further, it is possible to suggest that EcLPS exposure induces an early osteoblast differentiation of PDL-CD $105^{+}$cells as demonstrated by increased expression of RUNX2 and ALP transcripts at day 7 of osteogenic induction. In agreement with our data, the prolonged exposure to ECLPS upregulated ALP activity and calcium deposition in human bone marrow mesenchymal stem cells ${ }^{16}$, and could also promote an increase in osteogenic marker genes expression such as ALP, osteopontin and bone morphogenetic protein 2 (BMP-2) in adipose-derived stromal cells ${ }^{8}$.

In the present study, prolonged endotoxin exposure was designed to mimic a situation in which mesenchymal stem cells interact continuously with bacterial toxins during an inflammatory chronic disease, and then to evaluate whether this bacterial challenge could affect the osteogenic properties of periodontal ligament progenitor cells. Our findings suggest that CD105-enriched periodontal ligament progenitor cell populations acquire an adaptive tolerance under continuous LPS exposure. Previous studies reported endotoxin tolerance in oral mucosa cells associated with chronic periodontitis ${ }^{19}$. Also, transcripts for TLR2 and TLR4 were significantly downregulated in the gingival tissue of patients with chronic periodontitis, suggesting that the oral mucosa develops endotoxin tolerance in chronic periodontitis ${ }^{19}$. Interestingly, we also observed a downregulation of TLR4 in PDL-CD $105^{+}$cells under osteogenic induction associated to $E$. coli LPS exposure (data not shown).

However, further studies are required to elucidate the biological mechanism involved in the adaptive response by $\mathrm{CD} 105$-enriched periodontal ligament progenitor cells under continuous endotoxin exposure.

\section{CONCLUSIONS}

In conclusion, the results provide evidence that CD105-enriched PDL progenitor cells are able to adapt to continuous Escherichia coli endotoxin challenge, leading to an upregulation of osteogenic activities.

\section{ACKNOWLEDGEMENT}

The authors would like to thank São Paulo Research Foundation (FAPESP, São Paulo, SP, Brazil) for supporting author MLA. The authors report no conflicts of interest related to this study.

\section{REFERENCES}

1- Akira S, Takeda K. Toll-like receptor signalling. Nat Rev Immunol. 2004;4(7):499-511.

2- Dominici M, Le Blanc K, Mueller I, Slaper-Cortenbach I, Marini $F$, Krause $D$, et al. Minimal criteria for defining multipotent mesenchymal stromal cells. The International Society for Cellular Therapy position statement. Cytotherapy. 2006;8(4):315-7.

3- Fortino VR, Chen RS, Pelaez D, Cheung HS. Neurogenesis of neural crest derived periodontal ligament stem cells by EGF and bFGF. J Cell Physiol. 2014;229(4):479-88.

4- Gronthos S, Mankani M, Brahim J, Robey PG, Shi S. Postnatal human dental pulp stem cells (DPSCs) in vitro and in vivo. Proc Natl Acad Sci U S A. 2000;97(25):13625-30.

5- Guo C, Yuan L, Wang JG, Wang F, Yang XK, Zhang FH, et al. Lipopolysaccharide (LPS) induces the apoptosis and inhibits osteoblast differentiation through JNK pathway in MC3T3-E1 cells. Inflammation. 2014;37(2):621-31.

6- Huang GT, Gronthos S, Shi S. Mesenchymal stem cells derived from dental tissues vs. those from other sources: their biology and role in regenerative medicine. J Dent Res. 2009;88(9):792-806. 
7- Huang RL, Yuan Y, Zou GM, Liu G, Tu J, Li Q. LPS-stimulated inflammatory environment inhibits BMP-2 induced osteoblastic differentiation through crosstalk between TLR4/MyD88/NF-KB and BMP/Smad signaling. Stem Cells Dev. 2014;23(3):277-89.

8- Hwa Cho H, Bae YC, Jung JS. Role of toll-like receptors on human adipose-derived stromal cells. Stem Cells. 2006;24(12):2744-52. 9- Jones KJ, Ekhlassi S, Montufar-Solis D, Klein JR, Schaefer JS. Differential cytokine patterns in mouse macrophages and gingival fibroblasts after stimulation with Porphyromonas gingivalis or Escherichia coli lipopolysaccharide. ] Periodontol. 2010;81(12):1850-7.

10- Jönsson D, Nebel D, Bratthall G, Nilsson BO. LPS-induced MCP-1 and IL- 6 production is not reversed by oestrogen in human periodontal ligament cells. Arch Oral Biol. 2008;53(9):896-902. 11- Kadono H, Kido J, Kataoka M, Yamauchi N, Nagata T. Inhibition of osteoblastic cell differentiation by lipopolysaccharide extract from Porphyromonas gingivalis. Infect Immun. 1999;67(6):28416.

12- Kato H, Taguchi Y, Tominaga K, Umeda M, Tanaka A. Porphyromonas gingivalis LPS inhibits osteoblastic differentiation and promotes pro-inflammatory cytokine production in human periodontal ligament stem cells. Arch Oral Biol. 2014;59,167-75. 13- Li C, Li B, Dong Z, Gao L, He X, Liao L, et al. Lipopolysaccharide differentially affects the osteogenic differentiation of periodontal ligament stem cells and bone marrow mesenchymal stem cells through Toll-like receptor 4 mediated nuclear factor $\mathrm{\kappa B}$ pathway. Stem Cell Res Ther. 2014;5(3):67.

14- Martinez C, Rath S, Van Gulden S, Pelaez D, Alfonso A, Fernandez $N$, et al. Periodontal ligament cells cultured under steady-flow environments demonstrate potential for use in heart valve tissue engineering. Tissue Eng Part A. 2013;19(3-4):458-66. 15- Medzhitov R, Preston-Hurlburt $P$, Janeway CA Jr. A human homologue of the Drosophila Toll protein signals activation of adaptive immunity. Nature. 1997;388(6640):394-7.

16- Mo IF, Yip KH, Chan WK, Law HK, Lau YL, Chan GC. Prolonged exposure to bacterial toxins downregulated expression of Toll-like receptors in mesenchymal stromal cell-derived osteoprogenitors. BMC Cell Biol. 2008; 9:52.
17- Morsczeck C, Götz W, Schierholz J, Zeilhofer F, Kühn U, Möhl C, et al. Isolation of precursor cells (PCs) from human dental follicle of wisdom teeth. Matrix Biol. 2005;24(2):155-65.

18- Morsczeck CO, Drees J, Gosau M. Lipopolysaccharide from Escherichia coli but not from Porphyromonas gingivalis induce pro-inflammatory cytokines and alkaline phosphatase in dental follicle cells. Arch Oral Biol. 2012;57(12):1595-601.

19- Muthukuru M, Jotwani R, Cutler CW. Oral mucosal endotoxin tolerance induction in chronic periodontitis. Infect Immun. $2005 ; 73(2): 687-94$

20- Porada CD, Zanjani ED, Almeida-Porad G. Adult mesenchymal stem cells: a pluripotent population with multiple applications. Curr Stem Cell Res Ther. 2006;1(3):365-9.

21- Seo BM, Miura M, Gronthos S, Bartold PM, Batouli S, Brahim J, et al. Investigation of multipotent postnatal stem cells from human periodontal ligament. Lancet. 2004;364(9429):149-55.

22- Silvério KG, Rodrigues TL, Coletta RD, Benevides L, Silva JS, Casati MZ, et al. Mesenchymal stem cell properties of periodontal ligament cells from deciduous and permanent teeth. J Periodontol. 2010;81(8):1207-15.

23- Somerman MJ, Young MF, Foster RA, Moehring JM, Imm G, Sauk JJ. Characteristics of human periodontal ligament cells in vitro. Arch Oral Biol. 1990;35(3):241-7.

24- Sonoyama W, Liu Y, Yamaza T, Tuan RS, Wang S, Shi S, et al. Characterization of the apical papilla and its residing stem cells from human immature permanent teeth: a pilot study. J Endod. 2008;34(2):166-71.

25- Suaid FF, Ribeiro FV, Gomes TR, Silvério KG, Carvalho MD, Nociti $\mathrm{FH}$, et al. Autologous periodontal ligament cells in the treatment of Class III furcation defects: a study in dogs. J Clin Periodontol. 2012;39(4):377-84

26- Yamaji Y, Kubota T, Sasaguri K, Sato S, Suzuki Y, Kumada H, et al. Inflammatory cytokine gene expression in human periodontal ligament fibroblasts stimulated with bacterial lipopolysaccharides. Infect Immun. 1995;63(9):3576-81.

27- Yamamoto T, Kita M, Oseko F, Nakamura T, Imanishi J, Kanamura N. Cytokine production in human periodontal ligament cells stimulated with Porphyromonas gingivalis. J Periodontal Res. 2006;41(6):554-9. 